\title{
Zihinsel Durumların Dilde ve Bilişte Temsili*
}

\author{
Ercenur Ünal ${ }^{1}$, Özge Baturlar ${ }^{2}$ \\ ORCID ID: ${ }^{10000-0002-6794-2129, ~}{ }^{2} 0000-0001-6428-8953$ \\ Özyeğin Üniversitesi Nişantepe Mah. Orman Sk., 34794 Çekmeköy, İstanbul, \\ Türkiye \\ lercenur.unal@ozyegin.edu.tr, 2ozge.baturlar@ozyegin.edu.tr \\ (Gönderilme tarihi 18 Ocak 2020; kabul edilme tarihi 14 Mayls 2020)
}

\begin{abstract}
ÖZ: Başkalarının zihinsel durumlarını anlama becerisi okul öncesi çağlarda hızlı bir gelişim göstermektedir. Bu makalede dilin, kavramların çocukların zihinlerinde temsil edilişi ile ilişsisi ele alınmıştır. $\mathrm{Bu}$ ilişskiyi değerlendirebilmek için kişinin kendisinin ve başkalarının davranışlarına inanç, istek, niyet gibi zihinsel durumları atfetme becerileri (Theory of Mind) incelenmiştir. Özellikle dilin zihinsel durumların temsil edilmesinde gerekli olan kaynakları ne ölçüde sağladığı sorusuna odaklanılmıştır. Bu alandaki görgül bulgular dilin, zihinsel durumların temsilinde ve işlenmesinde kolaylaştırıcı bir araç görevi gördüğünü ancak zihinsel durumların temsili için bir zorunluluk olmadığını ortaya koymaktadır.
\end{abstract}

Anahtar sözcükler: zihin kuramı, yanlış inanç, yan cümlecik tümleci, dil-biliş etkileşimi, dil-düşünce ilişkisi

\section{Encoding Mental States in Language and Cognition}

ABSTRACT: The ability to understand others' mental states develops steadily during the preschool years. In this article, we consider how encoding mental states in language makes contact with mental state representations in cognition. To do so, we focus on Theory of Mind, the ability to attribute desires, intentions and beliefs to oneself and others. Specifically, we discuss the extent to which language provides the mental resources necessary for representing mental states. Empirical findings in this domain strongly suggest that language is not necessary for developing an understanding of mental states, but may be one of the many factors that facilitate the development of Theory of Mind.

Keywords: Theory of Mind, false belief understanding, sentential complementation, language-cognition interface

\footnotetext{
Makalenin ilk versiyonu üzerindeki önerileri için Canan Ergin ve Nihan Ketrez'e teşekkür ederiz.
} 


\section{Giriş}

Dünya dilleri, kavramları hangi yapılarla ve ne sıklıkta ifade ettikleri bakımından çeşitlilik gösterir. Bu makalede dildeki bu çeşitliliğin, zihnimizde kavramların temsil edilişi ile ilişkisini ele alacağız. Dil ile kavramların ilişkisi insan zihninin nasıl çalıştığını anlamaya yönelik araştırmaların merkezinde olmuştur ve dil-zihin ilişkisinin doğasına dair pek çok görüş ortaya atılmıştır (Gentner ve Goldin-Meadow, 2003; Gleitman ve Papafragou, 2012; Landau, Dessalegn ve Goldberg, 2010; Levinson, 2003; Lupyan, 2016; Ünal ve Papafragou, 2016a; ve Wolff ve Holmes, 2011).

Dilin, kavramların zihinde nasıl temsil edildiğini iki şekilde etkileyebileceği düşünülebilir. Birincisi, çevremizde bulunan nesnelerin ya da etrafımızda meydana gelen olayların pek çok farklı özelliği olsa da dil bu özelliklerin yalnızca bir bölümünü ifade ederek bu özelliklerin fark edilir hale gelmesine yardımcı olur. Başka bir deyişle dil ifade ettiği özellikler ve anlam farklılıkları yönünden seçicidir. Örneğin, Türkçede iki nesne arasındaki uzamsal ilişkileri ifade ederken bir nesnenin diğerini kapsadığı durumlarda içinde ilgeci (elma kâsenin içinde) kullanılır. Ancak Korecede uzamsal ilişkilerin ifadesi iki nesne arasındaki kapsama ilişkisinin ne kadar sıkı veya gevşek olduğu ayrımına odaklanır. Elmanın kâsenin içinde olması gibi gevşek bir ilişki ile kitabın kılıfının içinde olması gibi sıkı bir ilişki farklı fiiller kullanılarak ifade edilir. Sonuç olarak, dil kişinin dikkatini belli ayrımlara yönlendirerek kavramların zihinde nasıl temsil edildiğini etkileyebilir (Gentner ve Goldin- Meadow, 2003; Gleitman ve Papafragou, 2005; Landau vd., 2010; Wolff ve Holmes, 2011).

İkinci olarak ise dil, kavramların temsil edilmesi için bir araç olarak kullanılarak bilişsel becerileri destekleyebilir. Kavramlar zihinde dil haricinde görsel, işitsel, uzamsal ya da herhangi bir modaliteye bağlı olmayan çeşitli sözel olmayan kaynaklar aracılığıyla temsil edilebilir. Örneğin yan yana duran bir kâse ve elmanın nasıl bir konumda bulunduğu görsel olarak zihinde temsil edilebilir. Aynı nesnelerin konumu dil yoluyla da ifade edilebilir (elma kâsenin solunda). Bu şekilde dil, kavramların temsil edildiği ve saklandığı ek bir kodlayıcı işlevi görür. Dil ve sözel olmayan kaynaklar aracılığıyla meydana gelen bu temsiller, yalnızca sözel olmayan kaynaklara dayanan temsillere göre daha güçlü ve dayanıklı olabilir. Bu görüşe göre dil, kişilerin bilişsel kapasitesini güçlendiren veya zenginleştiren bir araç olarak düşünülebilir (Gentner ve Goldin-Meadow, 2003; Landau vd., 2010; Wolff ve Holmes, 2011). Burada esas tartışma, bu güçlendirici etkinin dile özgü olup olmadığ1 konusuna odaklanmaktadır. Bir görüşe göre dil yoluyla meydana gelen bu temsilleri başka yollarla, örneğin sözel olmayan bilişsel kaynaklara dayanarak, oluşturmak mümkün değildir (Carruthers, 2002). Dile daha zayıf bir rol atfeden bir başka görüşe göre ise dilin bu kolaylaştırıcı etkisi dilin sunduğu temsil 
sistemine özgü değildir ve dil, bilişsel kapasiteye destek veren farklı temsil sistemlerinden yalnızca biridir (Landau vd., 2010).

Bu makalede, dilin kavramların zihnimizde temsil edilişi ile ilişkisine dair bu ikinci hipotezi değerlendireceğiz. Bu hipotezi değerlendirmek için zihin kuramı (Theory of Mind) olarak bilinen zihinsel durumların dilde ve kavramsal düzeyde nasıl temsil edildiğine odaklanacağız. Zihin kuramı, kişinin kendisinin ve başkalarının davranışlarına inanç, istek, niyet gibi zihinsel durumlar atfetme ve bu inanç, istek ve niyetleri kişilerin davranışlarını açıklamak veya tahmin etmek için kullanabilme becerilerini kapsar (Baron-Cohen, Leslie ve Frith, 1985). Zihin kuramı ile ilgili bir diğer önemli nokta ise farklı kişilerin bir bilgiye farklı yollardan erişebileceklerini ve dolayısıyla aynı durum hakkında farklı inançları olabileceğini anlama becerisidir (Wellman, 2014). Bu nedenle kişilerin bazen durumlar hakkında yanlış inançları olabilir.

Erken çocukluk döneminde zihin kuramı gelişimi üzerine yapılan araştırmalar, genellikle çocukların, başkalarının yanlış inançlara sahip olabileceklerini anlama becerilerini (false belief understanding) ölçmeye yönelik yöntemler kullanır. Yanlış inanç testi olarak da bilinen bu çalışmalarda genellikle çocuklarla Sally-Ann testi adı verilen bir oyun oynanır (BaronCohen vd.,1985). Bu oyunda Sally isimli oyuncak bebek bir sepete bir misket koyar ve odadan ayrılır. Ardından Ann isimli diğer oyuncak bebek odaya girer ve sepetteki misketi çıkarıp bir kutunun içine koyar. Sally misketiyle oynamak için odaya geri döndügünde çocuklara Sally’nin misketi nerede arayacağ sorulur. Üç yaşındaki çocukların bu soruya yanıtı, Sally’nin misketi gerçekte bulunduğu yerde (yani kutunun içinde) arayacağı yönündedir. Ancak beş yaşındaki çocuklar, Sally’nin misketi, olduğunu düşündüğü yerde (yani sepetin içinde) arayacağını söylerler. Küçük çocukların başkalarının yanlış inançlarını kavrayabilme becerisindeki bu gelişimsel değişim pek çok araştırmada tekrar edilmiş bir bulgudur. (Bu konuda yapılan derlemeler için bakınız: Wellman, Cross ve Watson, 2001). Bazı araştırmalar ise, sözel soru-cevap yöntemi yerine çocukların beklentisini ölçebilmek için sözel olmayan davranışlara odaklanan ve bakış süresini temel alan paradigmalar kullanarak üç yaş öncesinde de yanlış inançları kavrayışın temellerinin görülebileceğini ortaya koymuştur (Buttelmann, Carpenter ve Tomasello, 2009; Onishi ve Baillargeon, 2005; Southgate, Senju ve Csibra, 2007; Surian, Caldi ve Sperber, 2007).

Zihinsel durumların dilde ve bilişte temsili, dil-biliş ilişsisinin doğasına dair hipotezleri test etmek için mükemmel bir olanak sunar. Bunun nedeni zihinsel durumları belirten düşünmek, bilmek, sanmak, inanmak gibi fiillerin tümce içinde kullanıldığında gösterdiği özelliklerdir. Bu fiiller yemek, yürümek, koymak gibi aksiyon belirten fiillere kıyasla anlamsal ve yapısal bakımdan farklılık göstermektedir. Zihinsel durumları belirten fiiller özellikle sözdizimi bakımından diğer fiillere kıyasla tümce içinde daha karmaşık bir yapıda 
kullanılır. Örneğin, bir kişinin yanlış bir inancını anlatmak için kişinin inancını ifade eden yan cümlecik sanmak fiilinin bulunduğu ana tümce içerisine yerleştirilir (Örnek 1). ${ }^{1}$

\begin{tabular}{|c|c|c|}
\hline (1) Ayşe bilye-(n)in & kova-da & ol-duğ-un-u \\
\hline $\begin{array}{l}\text { Ayşe bilye-TAM } \\
\text { san-(1)yor }\end{array}$ & kova-BUL & ol-TÜM-İYE.3TEK-BEL \\
\hline
\end{tabular}

Örnek (1)'deki, -dlk tümleyici eki ile belirtilen yan cümlecik bilyenin kovada olduğu, sanmak fiilinin tümleci görevindedir. Anlamsal olarak bakıldığında tümleç görevindeki yan cümlecik yanlış bir bilgi ifade etse dahi ana tümce anlamsal olarak doğrudur. Yan cümlecik tümleci olarak da bilinen bu sözdizimi, dil yoluyla yanlış bir inancın bir başkasının bakış açısından ifade edilebilmesine olanak sağlar.

Yukarıda anlatılan, dil-biliş ilişkisinin doğasına dair hipotezler zihinsel durumlar alanında da uygulanabilir. Yani, dil zihinsel durumların temsil edilmesi için bir araç olarak kullanılarak epistemik düşünme becerilerini destekleyebilir. Dilin bu destekleyici işlevinin doğasına dair iki görüş ortaya atılmıştır. Bir görüşe göre yan cümlecikle oluşturulan tümleçler, zihinsel durumların ve özellikle yanlış inançların, zihinde temsili için gerekli olan yapıyı sağlar (de Villiers, 2007; de Villiers ve de Villiers, 2000, 2009). Bir diğer görüşe göre ise zihinsel durum fiillerinin karmaşı sözdizimsel yapıları zihinsel durumların anlaşılması için gerekli olmasa da zihinsel durum ifadelerini kolaylaştıran pek çok araçtan biri olabilir. İlerleyen bölümlerde bu olasılıkları çeşitli katılımcı gruplarıyla yürütülen görgül bulgular ışı̆̆ında değerlendireceğiz.

\section{Sağır Çocuklarda ve Yetişkinlerde Zihin Kuramı}

Sağır çocuklar ve yetişkinler, zihin kuramının ne ölçüde dile bağlı olarak ve ne ölçüde dilden bağımsız olarak geliştiğini anlamak için önemli örneklemlerdir (Schick, de Villiers, de Villiers, ve Hoffmeister, 2007; de Villiers, 2005; Woolfe, Want, ve Siegal, 2002). Peterson ve Sigal (1999) sağır olup annebabası işaret dili bilmeyen beş yaşındaki çocukların sağır olmayan yaşıtlarına göre yanlış inanç testlerinde geri kaldıklarını ortaya koymuştur. Bunun yanı sıra, ailesi işaret dili bilmeyen sağır çocuklarla zihin kuramında belirgin güçlük

\footnotetext{
${ }^{1}$ Bu örnekte kullanılan kısaltmalar şu şekildedir: TAM: tamlayan durumu, BUL: bulunma durumu, TÜM: tümleyici, IYE: iyelik, 3: 3. kişi, TEK: TEKİL, BEL: belirtme durumu, ŞİM: şimdiki zaman
} 
yaşayan otizmli çocukların hemen hemen aynı performansı gösterdiklerini belirtmiştir. Aynı çalışmada sağır olup ailelerinde işaret dili bilen bir birey bulunan ve dolayısıyla işaret dilini anadili olarak öğrenen bir grup çocuk yanlış inanç testinde sağır olmayan yaşıtlarıyla aynı performansı göstermiştir. Bu çalışmalar dilden yoksun olmanın zihin kuramı gelişimiyle olumsuz yönde ilintili olabileceğini önermektedir. Bununla birlikle bu bulgular dilin hangi yönünün, yani genel dil becerisinin mi yoksa zihinsel durumları ifade eden dil becerisinin mi, zihin kuramı ile ilintili olduğunu net bir şekilde ortaya koymamaktadır.

Daha sonra Pyers ve Senghas (2009) Nicaragua'da işaret dilini geç yaşlarda edinen sağır bir grup yetişkin ile sürdürdükleri boylamsal bir çalışma ile yanlış inanç kavrayışı ve zihinsel durumları ifade eden terimlerin edinimi arasındaki ilişkiyi incelemişlerdir. İlk gözlem aşamasında yetişkin katılımcılara düşünmek, istemek, anlamak, bilmek gibi kavramları gösteren video kayıtları izletilmiş (örneğin: vazodaki çiçekleri almak istediği için eğilen bir kadın) ve katılımcılardan videodaki insanların zihinsel durumlarını tanımlamaları istenmiştir. Katılımcılar videolardaki insanların zihinsel durumlarını tanımlamak için hiçbir zihinsel durum fiili kullanmamıştır. Aynı katılımcılar yanlış inanç testlerinde de başarısız olmuşlardır. İki yıl sonra gerçekleşen ikinci gözlem aşamasında aynı katılımcıların zihinsel durumları ifade eden fiil kullanımının arttığı ve aynı zamanda yanlış inanç testindeki performanslarının gelişme gösterdiği gözlemlenmiştir. Bu bulgular 1şı̆̆ında Pyers ve Senghas zihinsel durumların temsilinin dil edinimine bağlı olduğunu ve sağır yetişkinlerin seneler boyu başkalarıyla sosyal etkileşimlerde bulunmalarına rağmen zihinsel durumları ifade eden terimlerden yoksun olmaları sebebiyle zihinsel durumları anlama becerilerinde gecikmeler olabileceğini öne sürmüşlerdir.

Ancak, bu verilere dayanarak yapılan yorumlar günümüzde tartışma konusu olmuştur. Öncelikle bu veriler 1şığında dil ve zihin kuramı becerisi arasında bir nedensellik ilişkisi ortaya koymak güçtür. Katılımcılar zihinsel durumları ifade eden fiilleri edindikleri için yanlış inanç testinde daha başarılı performans gösterebilecekleri gibi, yanlış inançları kavramsal düzeyde anlayabildikleri için zihinsel durumları ifade eden fiilleri ediniyor da olabilirler. Bunun yanı sıra, bu bulgular zihin kuramı gelişiminin ne ölçüde sosyal etkileşimlerden ne ölçüde dilden etkilendiğini ayrıştırmaya olanak sağlamamaktadır. Zihinsel durumları dil yoluyla ifade etmek doğrudan zihinsel durumlarla ilgili mantık yürütme becerilerini etkileyebileceği gibi, dil dolaylı yoldan da sosyal etkileşimlerin sıklığı, miktarı ve yoğunluğu gibi çeşitli niteliklerini etkileyebilir (Astington, 1996; Tomasello, 2009). Sonuç olarak, sağır çocuklarla ve yetişkinlerle yürütülen araştırmalar zihinsel durumların dil yoluyla ve kavramsal yoldan 
ifadeleri arasında bir ilişki olduğunu ortaya koysa da bu ilişkinin doğasını anlamak için yeterli değildir.

Bununla birlikte, gelişimsel alanyazına bakıldığında genel olarak zihinsel temsil becerileri için dil ediniminin gerekli bir koşul olması pek olası görünmemektedir. Örneğin, henüz dil yetileri kısıtlı olan 1 yaşındaki bebeklerle (örneğin, Onishi ve Baillargeon, 2005) ve hatta dil becerisi olmayan primatlarla (Krupenye, Kano, Hirata, Call ve Tomasello, 2016) yapılan araştırmalarda iki grubun da yanlış inanç kavrayışı ile ilgili temel becerilere sahip olduğu görülmüştür. $\mathrm{Bu}$ temel beceriler başka kişilerin inançlarıyla uyumlu şekilde davranacağı beklentisi ve bu beklentiyi başkalarının hem doğru hem de yanlış inançları için oluşturabilmeyi kapsar.

Bunun yanı sıra, zihin kuramının, zihinsel durumları ifade eden fiillerin gösterdiği diller-arası çeşitlilikten bağımsız geliştiğini gösteren bulgular vardır. $\mathrm{Bu}$ bulgulardan ilki, inanç ve istek kavramları arasındaki gelişim farkından gelir. Çocuklar istek kavramını (farklı bireylerin tutarsız istekleri dâhil) inançlardan (farklı bireylerin tutarsız inançları dâhil) önce anlarlar (Astington ve Gopnik, 1991; Flavell, 1988; Wellman, 1990). En önemlisi, kavramsal gelişimdeki bu örüntüler çocuğun anadilinde zihinsel durumları belirten fiillerin gösterdiği sözdizimi özelliklerinden bağımsız olarak gözlenmektedir. Örneğin, İngilizcede inanç ve istek belirten fiillerde yan cümlecikle oluşturulan tümleçlerde yapısal farklılar gözlenir. İstek belirten fiiller yan cümlecik tümleci kullanılmadan cümle içinde kullanılabilir (Örnek 2). İnanç belirten fiiller ise yan cümlecik tümleci ile kullanılır (Örnek 3$)^{2}$

(2). Ayşe wants

Ali to be home

Ayşe iste-ŞİM-3TEK Ali ol-EYL ev

'Ayşe Ali’nin evde olmasını istiyor'

(3) Ayşe thinks that Ali is home Ayşe san-ŞIM-3TEK TÜM Ali ol-ŞİM ev

'Ayşe Ali'nin evde olduğunu sanıyor'

Buna karşın, Almancada diğer kişilerin eylemleri hakkında istek belirtmek için kullanılan fiillerin tümleç oluşturma özellikleri (Örnek 4) ile inanç belirten fiillerin tümleç oluşturma özellikleri aynıdır (Örnek 5).

\footnotetext{
${ }^{2} \mathrm{Bu}$ örneklerde kullanılan kısaltmalar şu şekildedir: Şi̇M: şimdiki zaman, 3: 3. kişi, TEK: TEKİL, EYL: eylemlik, TÜM: tümleyici, BUL: bulunma durumu
} 
(4) Ayşe will dass Ali zu Hause ist Ayşe iste-Şİ TÜM Ali ev-BUL git-ŞİM-3TEK 'Ayşe Ali’nin evde olmasını istiyor'

(5) Ayşe glaupt dass Ali zu Hause ist Ayşe san-ŞİMTÜM Ali ev-BUL git-ŞİM-3TEK 'Ayşe Ali'nin evde olduğunu sanıyor'

Fakat hem anadili İngilizce olan hem de anadili Almanca olan çocuklar istek belirten fiilleri inanç belirten fiillerden daha erken konuşmaya ve anlamaya başlarlar (Perner, Sprung, Zauner ve Haider, 2003). Ayrıca, iki ayrı dili konuşan çocuklarda da istek kavramları inanç kavramlarından önce gelişmektedir (Bartsch ve Wellman, 1995). Bunun yanı sıra, yanlış inanç kavramının gelişimini ölçen hem geleneksel sözel cevaplama yöntemleri (Avis ve Harris, 1991; Liu, Wellman, Tardif ve Sabbagh, 2008; Tardif, Wellman ve Cheung, 2004) hem de yakın zamanda kullanılmaya başlanan bakış süresi yöntemleri (Barrett vd., 2013) bu becerinin gelişiminin anadilleri farklı olan çocuklarda benzer şekillerde ilerlediğini göstermiştir. Tüm bu bulgular, zihinsel durumların bilişte temsilinin zihinsel durumları dilde ifade eden terimlerin yapısal özelliklerine bağlı olarak gelişmediğine işaret etmektedir.

\section{Dil Odaklı Zihin Kuramı Eğitimleri}

Zihinsel durumları ifade eden fiiller ve bu fiillerin yapısal özellikleri zihinsel durumların kavramsal yönden temsil edilebilmesi için bir önkoşul olmasa da çocukların zihinsel durumları anlaması, hatırlaması ve bu kavramlarla ilgili başkalarıyla iletişim kurabilmesi gibi durumlarda kolaylaştırıcı bir unsur olabilir. Bu görüşü sınamak için yanlış inanç kavrayışının gelişiminin hem yan cümlecik tümleci kullanımı hem de diğer yollarla ne ölçüde desteklenebileceğini incelemek gerekir.

Bazı çalışmalar yanlış inanç testlerinde başarısız olan çocukların, sözel ve sözel olmayan çeşitli eğitimlerden sonra testleri başarıyla tamamladıklarını göstermiştir (Appleton ve Reddy, 1996; Clements, Rustin ve McCallum, 2000; Slaughter ve Gopnik, 1996). Fakat bu çalışmalar çocuklara cevaplarının neden doğru veya yanlış olduğunu açıklayan genel sözel geri bildirimler ile yan cümlecik tümleci gibi daha belirli dilsel yapılar üzerine yapılan geri bildirimler arasındaki olası farkları incelememiştir.

Okul öncesi dönemdeki çocuklarla yapılan dil odaklı zihin kuramı eğitimleri yan cümlecik tümleci yapısının yanlış inanç kavrayışı ile doğrudan ilişkisini test etmeye olanak sağlar. Örneğin, Lohmann ve Tomasello (2003) tarafından yürütülen bir çalışmada tümleç görevindeki yan cümleciklerin 
çocukların gerçeklik muhakemesi üzerine etkisini incelemiştir. Üç ve dört yaşlarındaki çocuklarla gerçekleştirilen bu çalışmada çocuklar belli bir obje gibi görünen ama gerçekte farklı olan objelerin (örneğin: çiçek gibi görünen bir kalem) yanıltıcı özellikleri ile ilgili farklı türlerde geri bildirim almışıtır. Tüm grup içinde yanlış inanç performansında en büyük gelişme, nesnelerin yanıltıcı özellikleri üzerine tümleç görevindeki yan cümlecik yapılarını kullanılarak verilenler geri bildirimleri alan çocuklarda görülmüștür. Yanıltıcı senaryolar olmadan yalnızca tümleç görevindeki yan cümlecik yapılarını duyan çocukların ve yanıltıcı özelliklerin basit bir dille anlatıldığ 1 çocuklarda da yanlış inanç performanslarında gelişme olmuştur. Son olarak yanıltıcı özelliklerin sözel olmayan yollarla anlatıldığı (örneğin araştırmacının objeye işaret ederek Bak! dediği ve objenin kalem olduğunu gösterip Şimdi bak! diyerek çocuğun dikkatini yönlendirildiği) grupta çocukların yanlış inanç performanslarında hiçbir gelişme kaydedilmemiştir. Araştırmacılar bu bulguları yanlış inanç kavrayışının gelişimi için hem nesnelerin yanıltıcı yönlerin deneyimlenmesinin hem de yan cümlecikle oluşturulan tümleçlerin ediniminin gerekli olduğu yönünde yorumlamışlardır.

$\mathrm{Bu}$ bulgular Hale ve Tager-Flusberg (2003) tarafindan yürütülen bir çalışmanın bulgularıyla benzerlik göstermektedir. Bu çalışmada, yanlış inanç testinde başarısız olan dört yaşındaki çocuklar yanlış inançlarla ilgili üç farklı şekilde eğitim almıştır. Birinci grupta çocuklar yanlış inanç testlerinde yanlış cevap verdiklerinde doğrulayıcı geri bildirimler almışlardır (Örnek 6). İkinci grupta çocuklar tümleç görevindeki yan cümlecik yapısını kullanmayı söylemek gibi iletişimsel ifadeler belirten fiilleri iletişimdeki yanlışları ifade etmek üzerine kullanma eğitimi almışlardır (Örnek 7). Üçüncü grupta ise çocuklar ortaç kullanımı üzerine eğitim görmüşlerdir (Örnek 8). ${ }^{3}$

(6) Kurabiye Canavarı kurabiye-ler-i

yatağ-in

Kurabiye Canavarı kurabiye-ÇOĞ-BEL yatak-TAM

alt-in-da

ara-(y)acak

alt-İYE-BUL

ara-GEL.3TEK

\footnotetext{
${ }^{3}$ Bu örneklerde kullanılan kısaltmalar şu şekildedir: ÇOĞ: çoğul, BEL: belirtme durumu, TAM: tamlayan durumu, IYE: iyelik, BUL: bulunma durumu, GEL: geleçek zaman, 3: 3. kişi, TEK: TEKİL, TÜM: tümleyici, GEÇ: geçmiş zaman, ORT: ortaç, YÖN: yönelme durumu
} 
(7) Çocuk Minik Kuş'u öp-tüğ-ün-ü

Çocuk Minik Kuş-BEL öp-TÜM-İYE.3TEK-BEL

ama aslında Kurabiye Canavar-1-(n)1

ama aslında Kurabiye Canavarı-İYE.3.TEK.BEL

söyle-di

söyleGEÇ.3TEK

öptü

öp-GEÇ.3TEK

(8) Büdì

$$
\text { zipla-(y)an }
$$

k1Z-a

saril-d1

Büdü

zıpla-ORT

k1z-YÖN

sarıl-GEÇ.3TEK

Sonuç olarak yanlış inanç üzerine eğitim alan birinci grubun ve yanlış-iletişim üzerine eğitim alan ikinci grubun, eğitim öncesi ve sonrası yapılan testlerde büyük ölçüde gelişim kaydettiği görülmüştür; fakat ortaç kullanımı üzerine eğitim alan üçüncü grup, eğitim sonrasında yapılan testte de başarısız olmuştur.

Tüm bu bulgular dilin, özellikle de yanlış inançları dil yoluyla ifade etmeye olanak sağlayan yan cümlecik tümleci gibi sözdizimsel yapıların, yanlış inanç kavrayışının gelişimini desteklediği ve kolaylaştırdığını destekler niteliktedir. Bununla birlikte, bu bulgular sözel olmayan çeşitli eğitimlerin de yanlış inanç kavrayışını desteklediğini göstermektedir. Bu bakımdan dilin ve yan cümlecik tümleci gibi yapıların yanlış inanç gibi zihinsel durumların kavramsal düzeyde ifadesi için gerekli olan tek araç olmadığına da işaret etmektedir.

Nitekim okul çağındaki çocuklarla yürütülen dil odaklı zihin kuramı eğitimlerinden edinilen bulgular bu görüşü destekler niteliktedir. Yakın zamanda tamamlanan bir eğitim çalışmasında de orta çocukluk dönemindeki müdahale grubu ve kontrol grubu olarak ayrılmak üzere iki grup çocuk ortalama 45 dakika süren 4 oturuma katılmıştır (Lecce, Bianco, Devine, Hughes ve Banerjee, 2014). Bu dört oturumda çocuklar bir araştırmacı eşliğinde 6-8 kişilik gruplara ayrılmış ve yanlış anlama, blöf, gaf yapma ve iğneleme gibi farklı zihinsel durumları her durum için ikişer hikâye üzerinden tartışmışlardır. Bunun yanı sira her oturumda anlama, bilme, inanma gibi zihinsel durumları ifade eden fiillerle ilgili dil aktiviteleri grup olarak tamamlamışlardır. Eğitim öncesinde yapılan değerlendirmede katılımcıların zihin kuramı becerileri ve buna ek olarak yürütücü işlevler, okuduğunu anlama becerisi ve sözel beceri gibi kontrol değişkenleri ölçülmüştür. Eğitim sonrasında ise zihin kuramı becerileri tekrar ölçülmüş ve eğitimin bu anlamdaki etkisi değerlendirilmiştir. Yapılan ön test ve son test sonucunda müdahale grubundaki çocukların zihin kuramı becerilerinde kontrol grubuna göre anlamlı ölçüde gelişme gösterdiği gözlemlenmiş ve bu sonuçların 2 ay süreyle korunduğu anlaşılmıştır. Bunun yanı sıra eğitimin olumlu etkileri yaş, sosyoekonomik durum, yürütücü işlevler, okuduğunu anlama becerisi ve sözel becerideki bireysel farklılıklardan bağımsız olarak bulunmuştur.

Lecce ve Bianco (2018) tarafından yapılan bir diğer eğitim çalışması ise yürütücü işlevlerden birisi olan işleyen bellekteki bireysel farklılıkların zihin 
kuramı gelişimi üzerindeki düzenleyici etkisini araştırmıştır. Okul ortamında sınıf öğretmenleri tarafından uygulanan bu eğitimlerde bir önceki araştırmada kullanılan yöntem takip edilmiştir. Aynı şekilde, müdahale grubu ve kontrol grubundaki çocuklar iki hikâye ve iki dil aktivitesini grup içinde tartışmıştır. Müdahale grubundaki hikâye ve aktiviteler zihinsel durumlar ile ilgili iken, kontrol grubundaki hikâye ve aktiviteler fiziksel olaylar ile ilgili hazırlanmıştır. İki araştırmanın yöntemsel açıdan tek farkı, ilkinde oturumları yöneten kişi araştırmacıyken, ikinci araştırmada oturumları yöneten kişinin sınıf öğretmeni olmasıdır. Araştırmanın bulguları eğitimin zihin kuramını desteklediği ve işleyen bellek becerilerindeki bireysel farklılıkların zihin kuramındaki ilerlemeyi düzenlediğini göstermiş̦tir. Erken çocukluk dönemindeki eğitim çalışmalarında olduğu gibi orta çocukluk döneminde yürütülen bu çalışmalarda da zihinsel durumları ifade eden terimlerin zihin kuramı gelişimini olumlu yönde desteklediği öne sürülebilir. Ancak orta çocukluk döneminde yürütülen dil odaklı eğitimlerin hangi nedenlerden ötürü zihin kuramı becerilerini desteklediğini belirlemek mümkün değildir. Bunun nedeni eğitimlerde hem zihinsel durumları ifade eden sözcüklerle ilgili dil egzersizlerinin yapılmış olması de hem grup halinde farklı zihinsel durumlarla ilgili tartışmalar yapılmış olmasıdır. Eğitime katılan çocukların zihin kuramı becerilerinde kaydettikleri gelişmeler sözcük egzersizlerinden, bu sözcükleri iletişim ortamında kullanımından ya da dilsel iletişimin olanak sağladığ sosyal etkileşimden kaynaklanıyor olabilir. $\mathrm{Bu}$ çalışmaların sonucunda dilin zihin kuramı gelişiminde benzersiz bir kolaylaştırıcı rolü olduğunu söylemek güç olsa da, bu bulgular dilin zihinsel durumların ifadelerini destekleyen ve kolaylaştıran birçok etmenden biri olabileceğine işaret etmektedir.

\section{Yetişkinlikte Zihin Kuramı}

Dil ile zihinsel durumlar hakkında mantık yürütme arasındaki ilişki zaman içinde nasıl gelişimsel değişimler izler? Bir görüşe göre, dil bu iki beceri bilişsel açıdan olgunluğa ulaşıncaya, yani yetişkinlik dönemine, kadar zihinsel durumların temsili için tamamlayıcı veya kolaylaştırıcı bir işlev görüyor olabilir. Ancak zihinsel durumlar hakkında mantık yürütme yetileri belli bir olgunluğa ulaştıktan sonra dilin kolaylaştırıcı etkisine ihtiyaç kalmaz. Bir diğer olasılık ise dilin yetişkinlik döneminde bile zihinsel durumlar hakkında mantık yürütme için gerekli olduğudur. $\mathrm{Bu}$ görüsse göre yetişkinler yanlış inanç testlerinde başarılı performans sergileyebilmek için dili yanlış inanç testini tamamladıkları sırada kullanmaya ihtiyaç duyacaklardır ve hatta dili kullanamadıkları durumda performanslarında düşüş gözlemlenecektir.

Íkili test paradigması (dual task paradigms) bu birbirine zıt görüşleri değerlendirmek için uygun bir yöntemdir. Bu paradigmada katılımcılar sözel 
olmayan bir görevi tamamlarken bir yandan da dil becerilerini meşgul eden sözel bir ikinci görev tamamlarlar (verbal interference task). Örneğin, bir yandan görsel hafiza ile ilgili bir test yaparken bir yandan iki basamaklı üç sayıyı (örn: 45, 93, 77) tekrar ederler (Trueswell ve Papafragou, 2010). Eğer dil, bilişsel bir görevi yerine getirmek için gerekli ise, katılımcının dile erişimini engelleyen ikinci bir görev verildiğinde bu görevin verilmediği durumlara göre katılımcının performansının düşmesi beklenir. Ancak bu düşüşün aynı anda bir yerine iki görev tamamlamaktan mı yoksa dile erişimin engellenmesinden mi kaynaklandığından emin olmak için sözel olmayan bir ikinci görev (non-verbal interference task) verildiğinde performansın nasıl etkilendiğini de gözlemlemek gerekir (Frank, Fedorenko, Lai, Saxe ve Gibson, 2012; Hermer- Vasquez, Spelke ve Katsnelson, 1999; Trueswell ve Papafragou, 2010; Winawer vd., 2007). Dile erişime müsaade eden sözel olmayan ikinci görevde performansın tekrar artması durumunda dilin anlık kullanımının birincil bilişsel görevi yerine getirmek için gerekli olduğu sonucuna varılır.

İkili test paradigmasını kullanan bir araştırmada, yetişkin katılımcılar bir yandan Sally-Ann yanlış inanç testini bir yandan da iki farklı ikinci görevden birini tamamlamıştır (Newton ve de Villiers, 2007). Bir grup katılımcı sözel bir ikinci görev yerine getirirken (verilen metinde işaretlemeler yapmak) diğer grup sözel olmayan bir ikinci görev (ritim tutmak) yerine getirmiştir. Sally'nin doğru inançlarını temel alan durumlarda iki gruptaki katılımcıların performansları fark göstermezken, Sally'nin yanlış inançlarını temel alan durumlarda yalnızca sözel olan ikinci görevi tamamlayan grubun performansında düşüş gözlenmiştir. Newton ve de Villiers'e göre bu bulgular, dilin yetişkinlikte de yanlış inanç kavrayışı için gerekli olduğu görüşünü destekler niteliktedir.

İkili test paradigmalarından edinilen bulguların doğru yorumlanabilmesi için sözel olan ve sözel olmayan ikinci görevlerin zorluk derecelerinin eşdeğer olması önem taşır. Dungan ve Saxe (2012) Newton ve de Villiers'ın çalışmalarında kullandıkları sözel ve sözel olmayan görevlerin farklı zorluk derecesinde olduklarının altını çizerek bulgular ışığında yapılan çıkarımları sorgulamışlardır. Nitekim aynı yanlış inanç testini zorluk dereceleri eşleştirilmiş sözel ve sözel olmayan ikinci görevler eşliğinde verdiklerinde, iki katılımcı grubu da benzer performans göstermiştir (Dungan ve Saxe, 2012). Sonuç olarak, önceki çalışmada öne çıkan yanlış inanç testindeki performans düşüşü, yetişkinlerin dile erişiminin kısıtlanmasından ziyade verilen ikinci görevin zorluk derecesiyle açılanabilir.

Gramatik afazi hastası olan yetişkinlerle yapılan vaka analizi çalışmalarının bulguları da bu görüşü destekler yöndedir. Afazi inme, felç veya sol beyinde hasar sonucu ortaya çıkan bir dil ve konuşma bozukluğudur. Bu grubun önemli 
bir özelliği de beyin hasarı meydana gelmeden önce zihin kuramı gibi epistemik düşünme yetilerinin belli bir olgunluğa erişmiş oluşudur. Afazi hastaları ifade edici ve alıcı dil becerilerinde ciddi sorunlar yaşarlar (Apperly, Samson, Carroll, Hussain ve Humphreys, 2006; Menn, Obler ve Michelli, 1990; Varley ve Siegal, 2000, Varley, Siegal ve Want, 2001). Örneğin, genellikle tek sözcükten oluşan tümceler üretirler, fiilleri anlamada ve basit tümceler dâhil olmak üzere tümce yapılarının dilbilgisi bakımından uygun olup olmadığını yorumlamada sorun yaşarlar. Buna rağmen, afazi hastalarının yanlış-inanç testlerinde neredeyse kusursuz performans gösterdiği gözlemlenmiştir (Apperly vd., 2006; Siegal, Varley ve Want, 2001; Varley ve Siegal, 2000, Varley vd.., 2001). Bu bulgular dilin ya da zihinsel durumları ifade eden terimlerin bulunduğu dil yapılarının yetişkinlikte de yanlış inanç kavrayışı için gerekli olduğu görüşüne karşı düşmektedir. Bununla birlikte, yetişkinlerin zihin kuramı becerilerinden elde edilen bulgular dilin ya da yan cümlecik tümleci gibi dil yapılarının epistemik düşünme yetilerinin gelişiminde kolaylaştırıcı birçok unsurdan biri olduğunu destekler yöndedir.

\section{Sonuç}

Bu makalede zihin kuramının hem çocuklukta hem de yetişkinlikte dilde nasıl temsil edildiğine dair görgül bulguları inceledik. Amacımız epistemik düşünme yetilerinin gelişimi için dilin ne ölçüde gerekli olduğunu değerlendirmekti.

Giriş bölümünde de açıklandığı üzere dilin kavramların zihinde temsiliyle iki şekilde ilişkili olabileceği düşünülebilir. Birincisi, dil kavramların belli özelliklerini ifade ederek kişinin bu özelliklere dikkat etmesini ve bu özellikleri fark etmesini sağlar. İkincisi, dil sözel olmayan kaynaklara ek bir temsil sistemi sunarak bilişsel kapasiteyi güçlendiren veya sözel olmayan yollarla temsil edilmesi mümkün olmayan birtakım kavramların temsil edilebilmesini destekleyen bir araç olarak görülebilir. Bu aracın zihin kuramı gelişimi için bir gereklilik olup olmadığı alanyazında tartışma konusu olmuştur. Çocuklarla, yetişkinlerle, sağır ve beyin hasarlı bireylerle yürütülen araştırmaların yanlış inanç kavrayışının gelişiminde düşünmek ve inanmak gibi zihinsel durumları ifade eden fiillerin yapısal özelliklerinin rolünü inceleme olanağı sağlar. Sağır yetişkinler zihinsel durumları belirten işaretleri öğrendiklerinde (Pyers ve Senghas, 2009) veya çocuklar yan cümleciklerle oluşturulan tümleçleri kullanma üzerine eğitim aldıklarında (Hale ve Tager- Flusberg, 2003; Lohmann ve Tomasello, 2003), yanlış inanç performanslarında gelişme kaydedildiği görülmüştür. Benzer şekilde yetişkinlerin yanlış inanç testlerini tamamlarken dilsel kodlama yapabildikleri durumlarda daha başarılı performans gösterdiği bulunmuştur (Dungan ve Saxe, 2012; Newton ve de Villiers, 2007). Bununla birlikte, çocukların ve yetişkinlerin yanlış inanç performanslarının başka 
etkenlere bağlı olarak da değiştiği görülmüştür. Örneğin, yan cümlecik tümleci kullanımı ile ilgili olmayan eğitimlerin de yanlış inanç kavrayışını destekleyebildiği (Hale ve Tager- Flusberg, 2003; Lohmann ve Tomasello, 2004) ve beyin hasarı nedeniyle yan cümlecik tümleci yapısını kullanamayan yetişkinlerin de yanlış inanç testlerinde başarılı performans sergileyebildiği gözlemlenmiştir (Apperly vd., 2006; Siegal vd., 2001; Varley ve Siegal, 2000, Varley vd., 2001). Ayrıca anadili farklı olan çocuklar, dildeki zihinsel durum belirten ifadelerde sözdizimi farklılıkları olmasına rağmen, yanlış inanç anlamlandırmada aynı gelişimsel süreçlerden geçerler (Bartsch ve Wellman, 1995; Perner vd., 2003; Tardif ve Wellman, 2000). En çarpıcı bulgulardan biri ise yanlış inanç kavrayışının temellerinin bebeklerde dil ediniminden önce (Onishi ve Baillargeon, 2005) ve primatlarda (Krupenye vd., 2016) görülüyor olmasıdır. Tüm bu bulgular dilin, zihinsel durumların temsilinde ve işlenmesinde kolaylaştırıcı bir araç görevi görmesine rağmen yanlış inanç kavrayışının gelişimi için mutlak bir gereklilik olmadığına işaret etmektedir.

Dilin zihinsel durumların temsilini hangi mekanizmalar aracıllğıyla kolaylaştırdığı henüz net olarak bilinmemektedir. Ancak bu ilişkiye aracı olabileceği öngörülen çeşitli mekanizmalar vardır. Örneğin, çocukların başka kişilerle zihinsel durumlar hakkında yaptıkları konuşmalar sırasında dil (bilhassa da zihinsel durumları ifade eden terimler) insanların bir durum hakkındaki inanışları ve durum gerçekliği hakkında bilgi veren bir kaynak olarak görülebilir (Harris, 1996, 1999; Tomasello, 2009). Bu sayede çocuklar gerçek durum ve inanışlar arasındaki tutarlılık veya tutarsızlıkları belirten önemli noktalara dikkat edebilir ve yanlış inanç kavrayışını geliştirebilirler. Bunun yanı sıra, başkalarıyla iletişim kurmak sosyal etkileşime olanak sağlar ve çocuklara zihinsel durumları birbirinden ayırt eden noktalara hassasiyet kazanabilecekleri ortamlar sunabilir.

Dilin zihinsel durumların kavranması için bir gereklilikten ziyade kolaylaştırıcı birçok etkenden biri olduğu görüşü dil-biliş etkileşimini diğer bilişsel alanlarda inceleyen araştırmaların bulgularıyla da tutarlılık göstermektedir. Örneğin, anadili Türkçe olan kişiler bir bilgiyi doğrudan mı dolaylı yoldan $\mathrm{m}$ edindiklerine ait kaynak bilgilerini başkalarına aktarmak için dildeki kanıtsallık eklerinden ( $-m \iota s$ ve $-d l)$ faydalanırlar. Okul öncesi dönemde anadili Türkçe olan çocukların dildeki kanıtsallık eklerinin kullanma ve başkalarının bir bilgiyi doğrudan $\mathrm{m}$ dolaylı yoldan $\mathrm{m}$ edindiği kavrama becerileri arasında bir ilişki vardır (Aksu-Koç, 2009; Aksu-Aksu-Koç, ÖgelBalaban ve Alp, 2009; Ozturk ve Papafragou, 2016, Ünal ve Papafragou, 2016b). İngilizcede ise farklı kaynaklardan edinilen bilgileri dilbilgisi yoluyla olarak ayırt etmek zorunlu değildir. Ancak, dildeki bu farklılığa rağmen anadili Türkçe ve İngilizce olan yetişkinlerin bir olayı doğrudan $\mathrm{m}$ dolaylı yoldan $\mathrm{m} 1$ deneyimlediklerini hatırlarken aynı derecede hatalar yaptığı bulunmuştur 
(Ünal, Pinto, Bunger, ve Papafragou, 2016). Benzer bulgular hareket içeren olaylar (motion events; Gennari, Sloman, Malt ve Fitch, 2002; Papafragou, Hulbert ve Trueswell, 2008; Trueswell ve Papafragou, 2010), mekansal/uzamsal ilişkiler (spatial cognition; Li ve Gleitman, 2002; Li, Abarbanell, Gleitman ve Papafragou, 2011) ve nesne-madde ayrımı (objectsubstance distinction, Li, Dunham ve Carey, 2009) gibi farklı bilişsel alanlarda da görülür. Farklı bilişsel alanlar genelinde görgül bulgular, anadilleri farklı olan kişilerin bilişsel becerilerinde farklılıklar olabileceğini göstermektedir. Bunun yanı sıra bu farklılıklar çoğunlukla bu kavramların dilde nasıl ifade edildiğiyle paralellik göstermektedir. Ancak, yukarıda anlatıldığı gibi katılımcıların bilişsel bir görev yerine getirirken dilsel kodlamaya erişimleri ikinci bir sözel görev aracılığıyla engellendiğince diller arası farklılıklar azalmakta veya kaybolmaktadır (Ünal ve Papafragou, 2016a). Bu bulgular dil ve bilişsel becerilerin bir bilişsel görev yerine getirilirken anlık etkileşimlerde bulunabileceklerini ancak bu anlık etkileşimlerin bilişsel becerilerde kalıcı değişiklikler meydana getirmediğini gösterir. Sonuç olarak yanlış inanç kavrayışı ve diğer alanlardan edinilen bulgular dil-biliş etkileşimindeki ince nüanslara dikkat çekmektedir.

\section{Kaynaklar}

Aksu-Koç, A. (2009). Evidentials: An interface between linguistic and conceptual development. E. Lieven, J. Guo, N. Budwig, S. Ervin-Tripp, K. Nakamura ve S. Özçalışkan (Yay. haz.), Crosslinguistic approaches to the psychology of language: Research in the tradition of Dan Isaac Slobin içinde (s. 531-541). Mahwah, NJ: Lawrence Erlbaum.

Aksu-Koç, A., Ögel-Balaban, H., \& Alp, I. E. (2009). Evidentials and source knowledge in Turkish. New Directions for Child and Adolescent Development, 125, 13-28. doi: $10.1002 / \mathrm{cd} .247$

Apperly, I. A., Samson, D., Carroll, N., Hussain, S., \& Humphreys, G. (2006b). Intact first- and second-order false belief reasoning in a patient with severely impaired grammer. Social Neuroscience, 1(3-4), 334-328. doi: 10.1080/17470910601038693

Appleton, M., \& Reddy, V. (1996). Teaching three year-olds to pass false belief tests: A conversational approach. Social Development, 5(3), 275-291. doi: 10.1111/j.14679507.1996.tb00086.x

Astington, J. W. (1996). What is theoretical about the child's theory of mind?: A Vygotskian view of its development. P. Curruthers, \& P. K. Smith (Yay. haz.), Theories of theories of mind içinde (s. 184-199). New York: Cambridge University Press.

Astington, J. W., \& Gopnik, A. (1991). Theoretical explanations of children's understanding of mind. British Journal of Developmental Psychology, 9(1), 7-31. doi: 10.1111/j.2044-835X.1991.tb00859.x 
Avis, J., \& Harris, P.L. (1991). Belief-Desire Reasoning among Baka Children: Evidence for a Universal Conception of Mind. Child Development, 62(3), 460-467. doi: 10.1111/j.1467-8624.1991.tb01544.x

Baron-Cohen, S., Leslie, A. M., \& Frith, U. (1985). Does the autistic child have a "theory of mind?" Cognition, 21(1), 37-46. doi: 10.1016/0010-0277(85)90022-8

Barrett, H.C., Broesch, T., Scott, R. M., He, Z., Baillargeon, R., Wu, D., Bolz, M., Henrich, J., Setoh, P., Wang, J., Laurence, S. (2013). Early false-belief understanding in traditional non-Western societies. Proceedings of the Royal Society, 280(1755), 20122654. doi:10.1098/rspb.2012.2654

Bartsch, R., \& Wellman, H. (1995). Children talk about the mind. Oxford, United Kingdom: Oxford University Press.

Buttelmann, D., Carpenter, M., \& Tomasello, M. (2009). Eighteen-month-old infants show false belief understanding in an active helping paradigm. Cognition, 112(2), 337-342. doi: 10.1016/j.cognition.2009.05.006

Carruthers, P. (2002). The cognitive functions of language. Behavioral and Brain Sciences, 25(6), 657-726. doi: 10.1017/S0140525X02000122

Clements, W. A., Rustin, C., \& McCallum, S. (2000). Promoting the transition from implicit to explicit understanding: A training study of false belief. Developmental Science, 3(1), 88-92. doi: 10.1111/1467-7687.00102

Dungan, J., \& Saxe, R. (2012). Matched false-belief performance during verbal and nonverbal interference. Cognitive Science, 36(6), 1148-1156. doi: 10.1111/j.15516709.2012.01248.x

Flavell, J. H. (1988). The development of children's knowledge about the mind: From cognitive connections to mental representations. In J. W. Astington, P. L. Harris, \& D. R. Olson (Eds.), Developing theories of mind (pp. 244-267). New York, NY: Cambridge University Press.

Frank, M. C., Fedorenko, E., Lai, P., Saxe, R., \& Gibson, E. (2012). Verbal interference suppresses exact numerical representation. Cognitive Psychology, 64(1-2), 74-92. doi:10. 1016/j.cogpsych.2011.10.004

Gennari, S. P., Sloman, S. A., Malt, B. C., \& Fitch, W. T. (2002). Motion events in language and cognition. Cognition, 83(1), 49-79. doi:10.1016/S0010-0277(01)001664

Gentner, D. \& Goldin-Meadow, S. (2003). Language in mind: Advances in the study of language and thought. Cambridge, MA: MIT Press.

Gleitman, L. \& Papafragou, A. (2005). Language and thought. K. Holyoak \& R. Morrison (Yay. haz.), Cambridge handbook of thinking and reasoning içinde (s. 633-661). Cambridge, United Kingdom: Cambridge University Press.

Gleitman, L. \& Papafragou, A. (2012). New perspectives on language and thought. K. Holyoak \& R. Morrison (Yay. haz.), The Oxford handbook of thinking and reasoning içinde (2. Basım) (s. 543-568). New York, NY: Oxford University Press.

Hale, C. M., \& Tager-Flusberg, H. (2003). The influence of language on theory of mind: A training study. Development Science, 6(3), 346-359. doi: 10.1111/14677687.00289 
Harris, P. (1996). Desires, beliefs, and language. P. Carruthers \& P. K. Smith (Yay. haz.), Theories of Theories of Mind içinde (s. 283- 304). Cambridge: Cambridge University Press.

Harris, P. (1999). Acquiring the act of conversation: Children's developing conception of their conversational partner. M. Bennett (Yay. haz.), Developmental Psychology: Achievements and Prospects içinde (s. 89- 105). Philadelphia: Psychology Press.

Hermer-Vazquez L., Spelke E. S., \& Katsnelson A. (1999). Sources of flexibility in human cognition: Dual-task studies of space and language. Cognitive Psychology, 39(1), 3-36. doi:10.1006/cogp.1998.0713

Krupenye, C., Kano, F., Hirata, S., Call, J. \& Tomasello, M. (2016). Great apes anticipate that other individuals will act according to false beliefs. Science, 354(6308), 110-114. doi: $10.1126 /$ science.aaf 8110

Landau, B., Dessalegn, B., \& Goldberg, A. M. (2010) Language and space: Momentary interactions. P. Chilton \& V. Evans (Yay. haz.), Language, cognition, and space: The state of the art and new directions. Advances in Cognitive Linguistics Series içinde (s. 51-78). London, United Kingdom: Equinox Publishing.

Lecce, S., Bianco, F., Devine, R. T., Hughes, C., \& Banerjee, R. (2014). Promoting theory of mind during middle childhood: A training program. Journal of Experimental Child Psychology, 126, 52-67. doi: 10.1016/j.jecp.2014.03.002

Lecce, S., \& Bianco, F. (2018). Working memory predicts changes in children's theory of mind during middle childhood: A training study. Cognitive Development, 47, 71-81. doi: 10.1016/j.cogdev.2018.04.002

Levinson, S. C. (2003). Space in language and cognition: Explorations in linguistic diversity. Cambridge, United Kingdom: Cambridge University Press.

Li, P., Abarbanell, L., Gleitman, L., \& Papafragou, A. (2011). Spatial reasoning in Tenejapan Mayans. Cognition, 120(1), 33-53. doi:10.1016/j.cognition.2011.02.012

Li, P., Dunham, Y., \& Carey, S. (2009). Of substance: The nature of language effects on entity construal. Cognitive Psychology, 58(4), 487-524. doi:10.1016/j.cogpsych.2008.12.001

Li, P. \& Gleitman, L. (2002). Turning the tables: Language and spatial reasoning. Cognition, 83(3), 265-294. doi:10.1016/S0010-0277(02)00009-4

Liu, D., Wellman, H. M., Tardif, T., \& Sabbagh, M. A. (2008). Theory of Mind development in Chinese children: A meta-analysis of false-belief understanding across cultures and languages. Developmental Psychology, 44(2), 523-531. doi: $10.1037 / 0012-1649.44 .2 .523$

Lohmann, H., \& Tomasello, M. (2003). The role of language in the development of false belief understanding: A training study. Child Development, 74(4), 1130-1144. doi: 10.1111/1467-8624.00597

Lupyan, G. (2016). The centrality of language in human cognition. Language Learning, 66(3), 516-553.

Menn, L., Obler, L. K., \& Miceli, G. (1990). Agrammatic aphasia: A cross-language narrative sourcebook (Vol. 2). Amsterdam: John Benjamins.

Newton, A. M., \& de Villiers, J. G. (2007). Thinking while talking: Adults fail nonverbal false-belief reasoning. Psychological Science, 18(7), 574-579. doi: 10.1111/j.14679280.2007.01942.x 
Onishi, K. H., \& Baillargeon, R. (2005). Do 15-month-old infants understand false beliefs? Science, 308(5719), 255-258. doi: 10.1126/science.1107621

Ozturk, O. \& Papafragou, A. (2016). The acquisition of evidentiality and source monitoring. Language Learning and Development, 12, 199-230. doi: 10.1080/15475441.2015.1024834

Papafragou, A., Hulbert, J., \& Trueswell, J. (2008). Does language guide event perception? Evidence from eye movements. Cognition, 108(1), 155-184. doi:10.1016/j.cognition.2008.02.007

Perner, J., Sprung, M., Zauner, P., \& Haider, H. (2003). Want-that is understood well before think-that, say-that, and false belief: A test of de Villiers' linguistic determinism on German speaking children. Child Development, 74(1), 179-188. doi: 10.1111/1467-8624.t01-1-00529

Peterson, C.C., \& Siegal, M. (1999). Representing inner worlds: Theory of mind in autistic, deaf, and normal hearing children. Psychological Science, 10(2), 126- 9. doi: $10.1111 / 1467-9280.00119$

Pyers, J. E., \& Senghas, A. (2009). Language promotes false-belief understanding: Evidence from learners of a new sign language. Psychological Science, 20(7), 805812. doi: 10.1111/j.1467-9280.2009.02377.x

Schick, B., de Villiers, P., de Villiers, J., \& Hoffmeister, R. (2007). Language and theory of mind: A study of deaf children. Child Development, 78(2), 376-396. doi: 10.1111/j.1467-8624.2007.01004.x

Siegal, M., Varley, R., \& Want, S. (2001). Mind over grammar: Reasoning in aphasia and development. Trends in Cognitive Sciences, 5(7), 296-301. doi: 10.1016/S13646613(00)01667-3

Slaughter, V., \& Gopnik, A. (1996). Conceptual coherence in the child's theory of mind: Training children to understand belief. Child Development, 67(6), 2767-2788. doi: 10.1111/j.1467-8624.1996.tb01898.x

Southgate, V., Senju, A., \& Csibra, G. (2007). Action anticipation through attribution of false belief by two-year olds. Psychological Science, 18(7), 587-592. doi: 10.1111/j.1467-9280.2007.01944.x

Surian, L., Caldi, S., \& Sperber, D. (2007). Attribution of beliefs to 13-month-old infants. Psychological Science, 18(7), 580-586. doi: 10.1111/j.1467-9280.2007.01943.x

Tardif, T., Wellman, H. M., \& Cheung, K. M. (2004). False belief understanding in Cantonese-speaking children. Journal of Child Language, 31(4), 779-800. doi: $10.1017 / \mathrm{S} 0305000904006580$

Tomasello, M. (2009). The cultural origins of human cognition. Cambridge, MA: Harvard University Press.

Trueswell, J. C. \& Papafragou, A. (2010). Perceiving and remembering events crosslinguistically: Evidence from dual-task paradigms. Journal of Memory and Language, 63(1), 64-82. doi: 10.1016/j.jml.2010.02.006

Ünal, E., \& Papafragou, A. (2016a). Interactions between language and mental representations. Language Learning, 66(3), 554-580.doi: 10.1111/lang.12188

Ünal, E. \& Papafragou, A. (2016b). Production-comprehension asymmetries and the acquisition of evidential morphology. Journal of Memory and Language, 89, 179-99. doi:10.1016/j.jml.2015.12.001. 
Ünal, E., Pinto, A., Bunger, A. \& Papafragou, A. (2016). Monitoring sources of event memories: A cross-linguistic investigation. Journal of Memory and Language, 87, 157-176. doi: 10.1016/j.jml.2015.10.009

Varley, R., \& Siegal, M. (2000). Evidence for cognition without grammar from causal reasoning and 'theory of mind' in an agrammatic aphasic patient. Current Biology, 10(12), 723-726. doi: 10.1016/S0960-9822(00)00538-8

Varley, R., Siegal, M., \& Want, S. C. (2001). Severe impairment in grammar does not preclude theory of mind. Neurocase, 7(6), 489-493. doi: 10.1093/neucas/7.6.489

de Villiers, P. (2005). The role of language in theory-of-mind development: What deaf children tell us. J. W. Astington \& J. A. Baird (Yay. haz.), Why language matters for theory of mind içinde (s. 266-297). New York: Oxford University Press.

de Villiers, J. (2007). The interface of language and theory of mind. Lingua, 117(11), 1858-1878. doi: 10.1016/j.lingua.2006.11.006

de Villiers, J. G., \& de Villiers, P. A.. (2000). Linguistic determinism and the understanding of false beliefs. P. Mitchell \& K. Riggs (Yay haz.), Children's reasoning and the mind içinde (s. 189-226). Hove, England: Psychology Press.

de Villiers, J. G., \& de Villiers, P. A. (2009). Complements Enable Representation of the Contents of False Beliefs: The Evolution of a Theory of Theory of Mind. S. FosterCohen (Yay. haz.), Language Acquisition içinde (s. 169-195). London: Palgrave Macmillan UK. doi:10.1057/9780230240780_8

Wellman, H. M. (1990). The child's theory of mind. Cambridge, MA: MIT Press.

Wellman, H. M. (2014). Making Minds: How Theory of Mind Develops. New York: Oxford University Press.

Wellman, H.M., Cross, D., \& Watson, J. (2001). A meta-analysis of theory of mind development: The truth about false belief. Child Development, 72(3), 655-684. doi: 10.1111/1467-8624.00304

Winawer, J., Witthoft, N., Frank, M. C., Wu, L., Wade, A. R., \& Boroditsky, L. (2007). Russian blues reveal effects of language on color discrimination. Proceedings of the National Academy of Sciences, 104(19), 7780-7785. doi:10.1073/pnas.0701644104

Wolff, P. M. \& Holmes, K. J. (2011). Linguistic relativity. Wiley Interdisciplinary Reviews: Cognitive Science, 2(3), 253-265. doi:10.1002/wcs.104

Woolfe, T., Want, S. C., \& Siegal, M. (2002). Signposts to development: Theory of mind in deaf children. Child Development, 73(3), 768-778. doi: 10.1111/1467-8624.00437 